\title{
SIMULATION IMPROVES END-OF-LINE SORTATION AND MATERIAL HANDLING PICKUP SCHEDULING AT APPLIANCE MANUFACTURER
}

\author{
Neelesh Kale \\ Marcelo Zottolo \\ Production Modeling Corporation \\ 15726 Michigan Avenue \\ Dearborn, MI 48126, U.S.A.
}

\author{
Onur M. Ülgen \\ Edward J. Williams \\ Industrial \& Manufacturing Systems Eng. \\ Engineering Complex, University of Michigan - Dearborn \\ 4901 Evergreen Road \\ Dearborn, MI 48128, U.S.A.
}

\begin{abstract}
The most venerable and the most highly varied general application area in which simulation has frequently and repeatedly proved its economic value is the manufacturing sector of the economy. Manufacturing applications of simulation have included attention to complex issues of equipment and/or worker downtime, problems of facility layout, work and line balancing, bottleneck analysis, and material handling. Furthermore, simulation has proved itself capable of addressing productivity and efficiency improvement tasks in which these complexities overlap and interact. Historically, much of the success simulation has enjoyed in other economic sectors (e.g., service, transportation, and health care) has stemmed in large measure from the reputation it earned in the manufacturing sector. The manufacturing application described in this paper proved the cost-effective feasibility of designing sortation operations downstream of an assembly line, and scheduling SKU pickups there, with no risk of blockage of that line.
\end{abstract}

\section{INTRODUCTION}

The earliest (dating back to at least the early 1960's) and for long the most conspicuous application successes of discrete-event process simulation have been the manufacturing sector of the economy (Law and McComas 1998). Numerous authors have described and documented the successful use of simulation to address a wide range of industrial-engineering problems arising in a likewise wide range of manufacturing contexts. For example, (Bandinelli, Iacono, and Orsoni 2004) describes the application of simulation to the remote scheduling of production of railway switch point assemblies. (Altinkilinc 2004) documents the use of simulation to undertake the layout planning and scheduling of a job-shop production plant. As a third of many possible examples, (Habenicht and Mönch) discusses the evaluation of batch production scheduling strategies in a multi-product wafer fabrication unit via simulation.

In the present work, the production engineers and managers of a home-appliance manufacturing company undertook to improve the economy and reliability of sortation procedures and scheduling of material-handling movements downstream from the main assembly line. "Sortation" in this context refers to the proper arrangement of many different SKUs [stock-keeping units] for storage and/or for picking into individual customer orders (Tompkins et al. 2003). This sortation task and its associated material-handling tasks were of a complexity meriting discrete-event simulation analysis due to volatile product mix, the large number of SKUs, the high overhead costs (both equipment and personnel) to move and sort inherently heavy, bulky appliances, and the strict requirement that bottlenecks in sortation must never block the upstream assembly line.

\section{OVERVIEW OF MANUFACTURING AND SORTATION OPERATIONS}

In the manufacturing and subsequent sortation processes considered in this study, large heavy unwieldy home appliances arrived from the final assembly line to the sortation area. The sortation area comprised six transit lines, each in turn comprising two equivalent spurs (hence twelve spurs in all). The appliances, of many different SKU varieties (during any one shift, up to 46 distinct SKUs could leave the assembly line), arrived at the sortation area approximately twice per minute. Sortation involved taking them to storage or to order-picking with proper attention to SKU. The transport to be scheduled required the use of manually operated "clamp trucks" - rather like conventional forklift trucks (Lane 2001), but retrofitted with special "upper arm grippers" to avoid damage to the appliances. A unit of an isolated SKU could be transported singly if necessary, although at lower efficiency of the clamp truck and its driver. 
Preferably, if two or four appliances of identical SKU arrived in relatively close succession at the ends of the two spurs comprising one of the six lines, they could be scheduled for transport as a group. A pair of identical SKUs can be picked up together if they are adjacent side-to-side or front-to-back (but not diagonally), as shown in Figure 1 below.
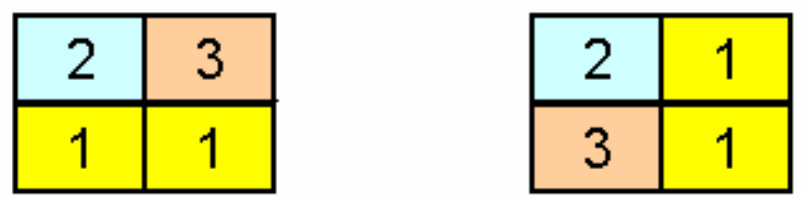

Figure 1: Configurations allow pickup of two SKU\#1

Due to the risks of cargo-load imbalance, it was unacceptable to transport three appliances on one foray, even if they were of identical SKU. The challenge confronting the engineers and the simulation study was to construct and validate a scheduling and operational procedure for routing various SKUs to the lines and spurs to forestall all risk of a sortation bottleneck blocking the assembly line, while using resources of clamp trucks and their drivers as thriftily and efficiently as possible.

\section{DATA COLLECTION AND ANALYSIS}

As up to 46 distinct SKUs could arrive at the sortation area in any one shift, the analysis team decided to collect product mix data from the production schedule for three months to estimate percentage quantity of each distinct SKU. The simulation analysts worked with the client's production planning and data control department to gather the most relevant and accurate data to estimate product mix. On request, the customer provided transport data such as pick up time for SKUs (1, 2, or 4 SKUs), travel time to warehouse, set down time for SKUs (1, 2, or 4 SKUs), and total number of clamp trucks and clamp truck uptime data.

The analysis started with the construction of a "base case" simulation model for the current sortation area with current total number of clamp trucks and current product mix. Subsequent scenarios were developed to change the product mix production schedule in accordance with the client's marketing predictions, and to maximize the number of SKUs per pickup while also leading to efficient use of clamp trucks via more nearly optimal scheduling of pickups.

In the proposed scenario \#1, clamp trucks were used to pick up two SKUs all the time irrespective of SKU type. This scenario caused extra travel for trucks in the storage area. More specifically, scenario \#2 was then developed using logic to sending an SKU to the spur having the same SKU type in its last occupied position. If there was no matching SKU in any of the spurs then the SKU was sent to the spur having the smallest current contents. Clamp trucks were utilized to pick up only two or four appliances at a time. Scenario \#3 was an extended version of scenario \#2 wherein, instead of six sorting lines (twelve spurs), up to ten sorting lines (twenty spurs) were analyzed. Any sorting line after number six would be used only if all of the first six lines were full.

The strategy used in the analysis was further changed to study sortation behavior in scenarios \#4 and \#5. According to the proportions of various SKUs in the product mix, each SKU was assigned to a sorting line. Hence, to balance usage of the six sortation lines, each should carry approximately $16 \%$ of the total number of SKUs. Product mix data were used to group SKUs to be routed to certain sorting lines. As a specific example, this logic stated that SKU types $1,2,3$, and 5 would be routed only to line 1 because product mix for these SKU types summed to very nearly $16 \%$. Scenario \#5 was run with ten sorting lines. As the number of sorting lines changed, SKU assignments for each line changed. In this case each line was allocated to carry $10 \%$ of total number of SKUs. Clamp trucks were then logically directed to pick up 1, 2, or 4 SKUs only, depending on the SKU type available at the end of a line. These scenarios gave scheduling priority preference to two or four SKU pick ups (instead of only one) in the interests of servicing as many SKUs as possible per trip and efficiently utilizing all available clamp trucks.

The scenarios \#6 and \#7 were extensions of scenarios \#4 and \#5 respectively. They differed only in that clamp trucks always picked up two or more SKUs per trip irrespective of SKU type.

\section{CONSTRUCTION, VERIFICATION, AND VALIDATION OF THE SIMULATION MODEL}

In accordance with client preference and the strength of the simulation software tool ProModel ${ }^{\circledR}$ for detailed materialhandling modeling, the client and consultant engineers jointly elected to use this tool. ProModel ${ }^{\circledR}$, like other modern simulation software tools, provides concurrent construction of the model and its animation, constructs such as Entities which move through the model, Locations to which they go, Resources which they use, plus powerful and intuitive constructs for modeling material-handling equipment and the network(s) within which such equipment operates (Harrell and Price 2003). A screen shot of the running simulation model appears as Figure 2. In this figure, the maze of blue lines represents travel routes and times between the warehouse (long rectangle at bottom of figure) and the twelve sortation lines shown. The performance metrics gathered dynamically during the run (righthand side of figure) provide statistics on the number of pickups, and classify these pickups as of one, two, or four items. The number in the yellow rectangle should remain zero - that is the number of blockages (an SKU tried and 
failed to enter the overcrowded sortation system) attributable to overly slow pickup service by the clamp trucks.

Verification methods applied to this model included modular development of the simulation model (to its credit, the ProModel ${ }^{\circledR}$ user interface encourages such development and makes it convenient), running the model with all randomness temporarily removed for ease of deskchecking results, running the model with only one entity, examination of the animation, use of directional analysis (e.g., verifying that if arrival rates increase and other input data remain unchanged, queue lengths should increase), and structured walkthroughs of the code segments within the model (Carson 2002).

Validation included running the model under current operating conditions and noting that the model predicted the necessity of three clamp truck trucks to avoid blockage of the assembly line. This threshold of three matched the client's experience and consequent current practice. Early in validation, a Turing test (Schruben 1980) exposed, and aided the correction of, an error relative to clamp- truck routing within the model network of paths. Also, the model prediction for "number of SKUs per pickup" slightly exceeded one, also matching current practice in which a clamp truck only rarely picked up more than one appliance per pickup. As an example of "extreme value validation," (Sargent 2004), the model was run under the unrealistic assumption that breakdowns never slowed or halted appliance flow from the main assembly line to the downstream sortation line. Under this hypothetical condition, model analysis showed that seven clamp trucks are needed to run the sortation area without blocking the assembly line. The prediction "seven clamp trucks needed" matched approximate spreadsheet calculations and the client's experience-based intuition.

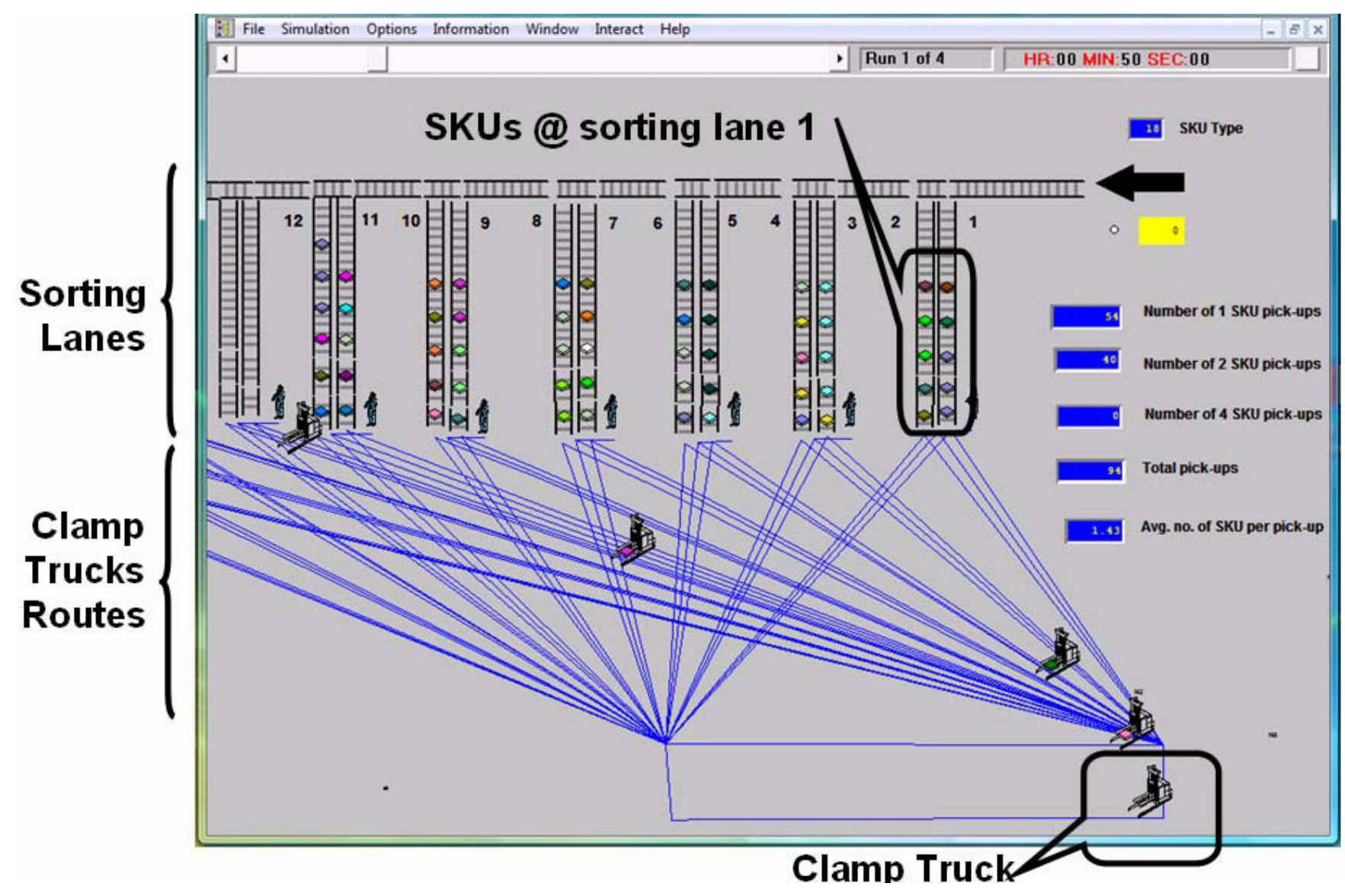

Figure 2. Annotated screen shot of ProModel $\AA$ model during simulation run 


\section{RESULTS AND INDICATED FURTHER WORK}

Simulation runs for the various scenarios were made as steady-state runs with a warm-up period of five production day and a data collection period of twenty production days (in practice, representing about one calendar month). To obtain sufficiently narrow confidence intervals (uncertainty for key performance metrics $<5 \%$ ), twelve replications of each scenario were made.

The key performance metric "percentage blockage for the upstream assembly line" was collected for each scenario with a varying number of clamp trucks, showing how many clamp trucks would be needed to minimize or eliminate assembly line blockage in each pickup-scheduling scenario.

Table 1: Comparison of base case and Scenario \#1

\begin{tabular}{|c|c|c|}
\hline $\begin{array}{c}\text { Number } \\
\text { of clamp } \\
\text { trucks }\end{array}$ & $\begin{array}{c}\text { Assembly line } \\
\text { AVG \% Blocked } \\
\text { (Baseline) }\end{array}$ & $\begin{array}{c}\text { Assembly line } \\
\text { AVG \% } \\
\text { Blocked } \\
\text { (Scenario \#1) }\end{array}$ \\
\hline 3 & $100.0 \%$ & $100.0 \%$ \\
\hline 4 & - & $55.1 \%$ \\
\hline 5 & $100.0 \%$ & $2.6 \%$ \\
\hline 6 & $25.2 \%$ & $0.0 \%$ \\
\hline 7 & $0.8 \%$ & $0.0 \%$ \\
\hline 8 & $0.0 \%$ & $0.0 \%$ \\
\hline
\end{tabular}

Proposed scenario \#1 predicted the need for least six clamp trucks to have no blockage of assembly.

Table 2: Comparison of Scenarios \#2 and \#3

\begin{tabular}{|c|c|c|}
\hline $\begin{array}{c}\text { Number } \\
\text { of clamp } \\
\text { trucks }\end{array}$ & $\begin{array}{c}\text { Assembly line } \\
\text { AVG \% Blocked } \\
\text { (Scenario \#2) }\end{array}$ & $\begin{array}{c}\text { Assembly line } \\
\text { AVG \% } \\
\text { Blocked } \\
\text { (Scenario \#3) }\end{array}$ \\
\hline 3 & $100.0 \%$ & $100.0 \%$ \\
\hline 5 & $100.0 \%$ & $52.8 \%$ \\
\hline 6 & $10.7 \%$ & $0.0 \%$ \\
\hline 7 & $0.0 \%$ & $0.0 \%$ \\
\hline
\end{tabular}

Proposed scenarios \#2 and \#3 likewise indicated that at least six clamp trucks would be needed to keep the assembly running without blockage.

Table 3: Comparison of Scenarios \#4 and \#5

\begin{tabular}{|c|c|c|}
\hline $\begin{array}{c}\text { Number } \\
\text { of clamp } \\
\text { trucks }\end{array}$ & $\begin{array}{c}\text { Assembly line } \\
\text { AVG \% Blocked } \\
\text { (Scenario \#4) }\end{array}$ & $\begin{array}{c}\text { Assembly line } \\
\text { AVG \% } \\
\text { Blocked } \\
\text { (Scenario \#5) }\end{array}$ \\
\hline 3 & $100.0 \%$ & $100.0 \%$ \\
\hline 4 & - & $7.3 \%$ \\
\hline 5 & $12.4 \%$ & $2.0 \%$ \\
\hline 6 & $1.3 \%$ & $0.0 \%$ \\
\hline 7 & $0.0 \%$ & $0.0 \%$ \\
\hline
\end{tabular}

Proposed scenarios \#4 and \#5 again showed that at least six clamp trucks would be needed to keep the assembly running without blockage.

Table 4: Comparison of Scenarios \#4 and \#6

\begin{tabular}{|c|c|c|}
\hline $\begin{array}{c}\text { Number } \\
\text { of clamp } \\
\text { trucks }\end{array}$ & $\begin{array}{c}\text { Assembly line } \\
\text { AVG \% Blocked } \\
\text { (Scenario \#4) }\end{array}$ & $\begin{array}{c}\text { Assembly line } \\
\text { AVG \% } \\
\text { Blocked } \\
\text { (Scenario \#6) }\end{array}$ \\
\hline $\mathbf{3}$ & $100.00 \%$ & $100.00 \%$ \\
\hline $\mathbf{5}$ & $12.35 \%$ & $0.82 \%$ \\
\hline $\mathbf{6}$ & $1.25 \%$ & $0.00 \%$ \\
\hline $\mathbf{7}$ & $0.00 \%$ & $0.00 \%$ \\
\hline
\end{tabular}

Table 5 indicated that the change from scenario \#4 to scenario \#6 (recall that this change entails only the scheduling of a clamp truck to pick up at least two SKUs per trip irrespective of SKU types) would allow reduction of the clamp truck fleet from six to five. Since the change from Scenario \#5 to Scenario \#7 was analogous, these two scenarios were compared next.

Table 5: Comparison of Scenarios \#5 and \#7

\begin{tabular}{|c|c|c|}
\hline $\begin{array}{c}\text { Number } \\
\text { of clamp } \\
\text { trucks }\end{array}$ & $\begin{array}{c}\text { Assembly line } \\
\text { AVG \% Blocked } \\
\text { (Scenario \#5) }\end{array}$ & $\begin{array}{c}\text { Assembly line } \\
\text { AVG \% } \\
\text { Blocked } \\
\text { (Scenario \#7) }\end{array}$ \\
\hline $\mathbf{3}$ & $100.00 \%$ & $100.00 \%$ \\
\hline $\mathbf{4}$ & $7.28 \%$ & $8.88 \%$ \\
\hline $\mathbf{5}$ & $2.04 \%$ & $0.80 \%$ \\
\hline $\mathbf{6}$ & $0.00 \%$ & $0.00 \%$ \\
\hline
\end{tabular}

The comparison between proposed scenario \#5 and \#7 again showed that the required number of clamp trucks could be reduced from six to five, here producing an acceptably small (less than $1 \%$ ) blockage, although not zero blockage. In both these scenarios, four clamp trucks prove inadequate, with the difference in percent blocked time (7.28\% versus $8.88 \%$ ) insignificant at the $5 \%$ significance level. Five clamp trucks perform noticeably better, especially in scenario 7 , which is now superior to scenario 5 at the $5 \%$ significance level $(2.04 \%$ versus $0.80 \%)$. The dramatic drop in blockage attainable by adding one or two more clamp trucks (typical of operations research results concerning congestion (Thomas and Wilson 2001)) was documented for the clients using graphs such as Figure 3. The client management became more comfortable with these results upon being provided this analogy from everyday experience: "Recall how the waiting line in a bank or post office can suddenly shrink if one more service window opens, or lengthen if one currently open service window closes."

The summarized results are shown in Table 6 . 
Table 6: Summarized results: \# clamp trucks needed

\begin{tabular}{|l|c|}
\hline \multicolumn{1}{|c|}{ Scenario Description } & $\begin{array}{c}\text { Required num- } \\
\text { ber of clamp } \\
\text { trucks }\end{array}$ \\
\hline Baseline scenario & 8 \\
\hline Proposed Scenario 1 (Pick 2) & 6 \\
\hline $\begin{array}{l}\text { Proposed Scenario 2 (Last posi- } \\
\text { tion) }\end{array}$ & 7 \\
\hline $\begin{array}{l}\text { Proposed Scenario 3 (20 sorting } \\
\text { lines) }\end{array}$ & 6 \\
\hline $\begin{array}{l}\text { Proposed Scenario 4 (SKU as- } \\
\text { signment) }\end{array}$ & 7 \\
\hline $\begin{array}{l}\text { Proposed Scenario 5 (20 Sorting } \\
\text { lines) }\end{array}$ & 6 \\
\hline $\begin{array}{l}\text { Proposed Scenario 6 (Pick 2, } \\
\text { SKU assignment) }\end{array}$ & 5 \\
\hline $\begin{array}{l}\text { Proposed Scenario 7 (Pick 2, 20 } \\
\text { sorting lines) }\end{array}$ & 5 \\
\hline
\end{tabular}

Effect of the Number of Clamp Trucks (Prop Scen +5 us. \#7)

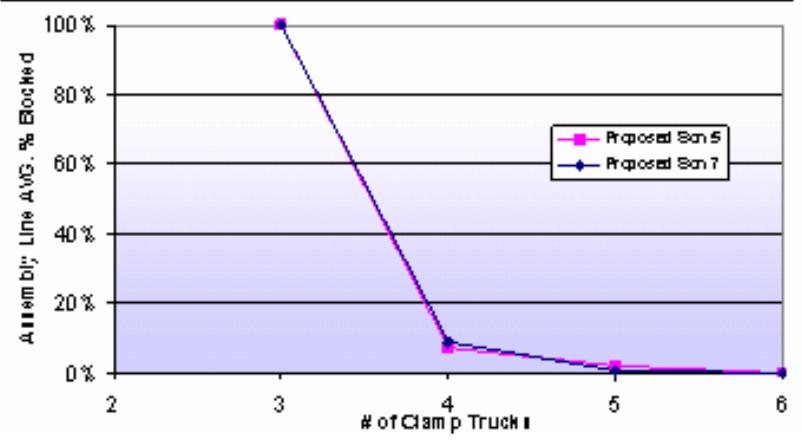

Figure 3: Graph showing dramatic drop in \%blockage when sufficient clamp trucks available

\section{ACKNOWLEDGMENTS}

The authors gratefully acknowledge the motivation and help of Professor Björn Johansson of Chalmers University, Göteborg, Sweden provided by urging the presentation of this application, suggesting the themes of this paper, and contributing valuable and explicit criticisms for its improvement.

\section{REFERENCES}

Altinkilinc, Mert. 2004. Simulation-Based Layout Planning of a Production Plant. In Proceedings of the 2004 Winter Simulation Conference, Volume 2, eds. Ricki G. Ingalls, Manuel D. Rossetti, Jeffrey S. Smith, and Brett A. Peters, 1079-1084.
Bandinelli, Romeo, Mauro Iacono, and Alessandra Orsoni. 2004. Improving the Remote Scheduling of Manufacturing and Installation of Large Custom-Made Products. In Proceedings of the $18^{\text {th }}$ European Simulation Multiconference, ed. Graham Horton, 334-339.

Carson, John S. II. 2002. Model Verification and Validation. In Proceedings of the 2002 Winter Simulation Conference, Volume 1, eds. Enver Yücesan, ChunHung Chen, Jane L. Snowdon, and John M. Charnes, 52-58.

Habenicht, Ilka, and Lars Mönch. 2004. Evaluation of Batching Strategies in a Multi-Product Waferfab by Discrete-Event Simulation. In Proceedings of the $16^{\text {th }}$ European Simulation Symposium, eds. György Lipovszki and István Molnár, 23-28.

Harrell, Charles R., and Rochelle N. Price. 2003. Simulation Modeling Using ProModel Technology. In Proceedings of the 2003 Winter Simulation Conference, Volume 1, eds. Stephen E. Chick, Paul J. Sánchez, David Ferrin, and Douglas J. Morrice, 1175-181.

Lane, David A. 2001. Industrial Engineering Support for Materials Management. In Maynard's Industrial Engineering Handbook, $5^{\text {th }}$ edition, ed. Kjell B. Zandin, 10.31-10.56. New York, New York: The McGrawHill Companies, Incorporated.

Law, Averill M., and Michael G. McComas. 1998. Simulation of Manufacturing Systems. In Proceedings of the 1998 Winter Simulation Conference, Volume 1, eds. D. J. Medeiros, Edward F. Watson, John S. Carson, and Mani S. Manivannan, 49-52.

Sargent, Robert G. 2004. Validation and Verification of Simulation Models. In Proceedings of the 2004 Winter Simulation Conference, Volume 1, eds. Ricki G. Ingalls, Manuel D. Rossetti, Jeffrey S. Smith, and Brett A. Peters, 17-28.

Schruben, L. W. 1980. Establishing the Credibility of Simulations. In Simulation 34: 101-105.

Thomas, Marlin U., and George R. Wilson. 2001. Applications of Queuing Theory. In Maynard's Industrial Engineering Handbook, $5^{\text {th }}$ edition, ed. Kjell B. Zandin, 11.67-11.99. New York, New York: The McGraw-Hill Companies, Incorporated

Tompkins, James A., John A. White, Yavuz A. Bozer, and J. M. A. Tanchoco. 2003. Facilities Planning, $3^{\text {rd }}$ edition. Hoboken, New Jersey: John Wiley \& Sons, Incorporated.

\section{AUTHOR BIOGRAPHIES}

NEELESH KALE received a bachelor of engineering degree in production engineering from the university of Pune, India (2000) and an M.S. degree in industrial engineering from Oklahoma State University, U.S.A. (2003) with a concentration in operations research and statistics. Currently he is working as a simulation analyst with Produc- 


\section{Williams, Zottolo, Kale, and Ülgen}

tion Modeling Corporation, Dearborn, Michigan. His interest areas are simulation modeling and analysis, production scheduling, and traditional industrial engineering techniques for performance improvement. He frequently uses Enterprise Dynamics ${ }^{\circledR}$, SIMUL8 ${ }^{\circledR}$, and WITNESS ${ }^{\circledR}$ simulation packages, and the ASPROVA ${ }^{\circledR}$ scheduling analysis software for modeling and analysis. He is a certified six sigma engineer (American Society of Quality). His e-mail address is $<$ nkaleepmcorp. com $>$.

MARCELO ZOTTOLO, born in Buenos Aires, Argentina, came to the United States to finish his college studies. He was graduated from the University of Michigan - Dearborn as an Industrial and Systems Engineer in December 2000, and subsequently earned his master's degree in the same field in June 2004. He was awarded the Class Honors distinction and his Senior Design Project was nominated for the Senior Design Competition 2001. This project studied the improvement of manufacturing processes for the fabrication of automotive wire harnesses, ultimately proposing an automation tool leading to improvements in future designs. Additionally, he was co-author of a paper on simulation in a distribution system which earned a "best paper" award at the Harbour, Maritime, and Simulation Logistics conference held in Marseille, France, in 2001. He is currently working for Production Modeling Corporation as a Consulting Project Manager, supervising less senior engineers in the delivery of simulation projects and results to a variety of clients. There, his responsibilities include building, verifying, validating, and analyzing simulation models in Enterprise Dynamics $\AA$, WITNESS $®$, ProModel ${ }^{\circledR}$, and SIMUL8 $\AA$ for large corporate clients, plus supervision of and instruction in all these tasks; he also presents in-house training seminars. His email address is <mzottolo@pmcorp.com>

ONUR M. ÜLGEN is the president and founder of Production Modeling Corporation (PMC), a Dearborn, Michigan, based industrial engineering and software services company as well as a Professor of Industrial and Manufacturing Systems Engineering at the University of MichiganDearborn. He received his Ph.D. degree in Industrial Engineering from Texas Tech University in 1979. His present consulting and research interests include simulation and scheduling applications, applications of lean techniques in manufacturing and service industries, supply chain optimization, and product portfolio management. He has published or presented more that 100 papers in his consulting and research areas. Under his leadership PMC has grown to be the largest independent productivity services company in North America in the use of industrial and operations engineering tools in an integrated fashion. PMC has successfully completed more than 3000 productivity improvement projects for different size companies including General Motors, Ford, DaimlerChrysler, Sara Lee,
Johnson Controls, and Whirlpool. The scientific and professional societies of which he is a member include American Production and Inventory Control Society (APICS) and Institute of Industrial Engineers (IIE). He is also a founding member of the MSUG (Michigan Simulation User Group). His email addresses are <ulgen@umich. edu> and <ulgen@pmcorp. com>.

EDWARD J. WILLIAMS holds bachelor's and master's degrees in mathematics (Michigan State University, 1967; University of Wisconsin, 1968). From 1969 to 1971, he did statistical programming and analysis of biomedical data at Walter Reed Army Hospital, Washington, D.C. He joined Ford Motor Company in 1972, where he worked until retirement in December 2001 as a computer software analyst supporting statistical and simulation software. After retirement from Ford, he joined Production Modeling Corporation, Dearborn, Michigan, as a senior simulation analyst. Also, since 1980, he has taught evening classes at the University of Michigan, including both undergraduate and graduate simulation classes using GPSS $/ \mathrm{H}^{\mathrm{TM}}$, SLAM II $^{\mathrm{TM}}$, SIMAN ${ }^{\mathrm{TM}}$, ProModel ${ }^{\circledR}$, SIMUL8 $\AA$, or Arena ${ }^{\circledR}$. He is a member of the Institute of Industrial Engineers [IIE], the Society for Computer Simulation International [SCS], and the Michigan Simulation Users' Group [MSUG]. He serves on the editorial board of the International Journal of Industrial Engineering - Applications and Practice. During the last several years, he has given invited plenary addresses on simulation and statistics at conferences in Monterrey, México; İstanbul, Turkey; Genova, Italy; Rīga, Latvia; and Jyväskylä, Finland. He has served as Program Chair of the 2004, 2005, and 2006 Summer Computer Simulation Conferences, and for the 2005 IIE Simulation Conference; and will be program chair for the simulation track of the IIE 2008 annual conference. E-mail address and university web pages: <ewilliams@pmcorp. com> and <http://www-personal.umd.umich. edu/ williame $>$. 